Preproof. Please cite the published version: Caleb Ward and Ellie Anderson, "The Ethical Significance of Being an Erotic Object," in The Palgrave Handbook of Sexual Ethics, David Boonin (ed.), (London: Palgrave, 2022), 55-71.

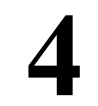

\title{
The Ethical Significance of Being an Erotic Object
}

\section{Caleb Ward and Ellie Anderson}

Contemporary philosophical discussions of sexual ethics focus heavily on questions of autonomy, agency, and the moral power of consent. Since the late 1980s, moral and legal theorists have debated the conditions of moral validity for sexual consent, while feminist social and legal theorists have for even longer criticized social practices and institutional structures that undermine the agency of women to steer their sexual lives. Common across these discussions is the hope that respect for another's freedom, autonomy, or will can prevent the harm of objectification, that is, treating another merely as a sexual object or means. The task of sexual ethics, on the conventional view, becomes reconciling one's grasp of another as an object of erotic desire with the moral authority of their subjectivity. This generally involves placing their subjectivity above their status as object, so as to avoid the danger of objectification.

However, we are always both subject and object in our encounters with others. As a result, theorists disregard essential, morally relevant features of intimacy when they locate the moral significance of another only in their active subjectivity. In this chapter, we argue for a methodological adjustment to sexual ethics that widens the narrow focus on freedom, autonomy, and agency to address the moral significance of being an erotic object as well. Drawing on phenomenology, particularly the insights of Simone de Beauvoir, we propose an approach that recognizes a constitutive ambiguity between the freedom appropriate to subjectivity and the phenomenon of being an erotic object in intimate encounters. While we are committed to the 
feminist view that all people should have agency over their sexual lives, we reject the conflation of this commitment with the idea that the autonomous will is the sole source of another's moral authority in sexual intimacy. Important moral features of intimacy are disclosed through the erotic experiences of both being an object and perceiving another as object, and the ethical implications of objecthood remain unexamined when the division between moral subject and erotic object is too sharply defined. By engaging with the ethics of erotic objecthood, theories of sexual ethics can become more adequate phenomenologically and more sensitive to the complexity of intimacy, even as they work to capture the moral significance of agency and to acknowledge the wrongs of sexual violation.

We proceed in three sections. Section one examines how being an erotic object to another is experienced in sexual intimacy, particularly how it is intertwined with one's sense of active agency or subjectivity. We interpret this situation as an example of what Beauvoir describes as ambiguity, that is, the simultaneous sense of being a free subjectivity and being exposed as a corporeal object to others. Section two articulates a distinction between the wrongs associated with the term 'objectification' in philosophical debates, and the other-as-object valency of both perception and treatment of others in sexual intimacy. A person is encountered as an object unlike other objects, but not in the sense that they appear as a moral person endowed with a rational will. Instead, another person approaches one as a synthetic whole that discloses both subjectivity and bodily presence. Section three argues that the fact that being an object is inextricable from subjectivity or personhood ought not to be overlooked in theorizing sexual ethics. Being an erotic object is morally significant for two reasons. First, my erotic objecthood plays a central role in the explicit claims that I as an agential subject make on another, such as the claims I make by intentionally communicating sexual affirmation or refusal. Second, to grasp another as an erotic object is to be 
solicited morally by another, even absent the authoritative expressions of will familiar from standard accounts of sexual ethics.

\section{Living one's ambiguity and being an object for others}

Philosophical discussions of the ethics of sexual intimacy often focus on how and why a person wrongs another by failing to gain valid consent or to respect refusal. Often, these wrongs are articulated in terms of treating another as a mere object, or means, rather than as a person worthy of respect. This approach has been supported by feminist accounts of the experience of sexual violation that focus on how violation renders one passive or inert in the face of another's unwanted sexual behaviors. ${ }^{1}$ However, in discussions of sexual ethics, philosophers rarely reflect on situations where feeling like an erotic object is not experienced as violating. Feeling like an object need not entail feeling used or harmed; indeed, being an erotic object for another is a central feature of virtually all erotic encounters. In this section, we analyze the structure of being an erotic object using the phenomenological concept of ambiguity. We suggest that being an object plays a constitutive role in experiences of sexual selfhood and agency in general, which merits consideration in sexual ethics.

The idea that selfhood is ambiguous comes from phenomenology, a philosophical method that describes phenomena as they appear in lived experience - that is, in the first-person perspective of an embodied perceiver in the world. Simone de Beauvoir uses ambiguity to characterize an irreducibly dual character of human experience: as living in a world always shared with others, persons are unavoidably both subjects (for themselves) and objects (for others). Persons are ambiguous because they experience themselves as being a unique perspective on the world, with a sense of agency and in a process of becoming over time; and yet they also experience being 
objects within the world, affected by their environments and showing up in others' horizons of experience. That is, persons are both transcendent (or free) and immanent (or limited by being bound up in a situation with others to whom they are vulnerable). Beauvoir describes ambiguity as "that engaged freedom, that surging of the for-oneself which is immediately given for others." Freedom can only exist engaged in a world, where it always depends on others both for its practice and for its products to have meaning.

As a free being, I transcend my situation; but, because I am also a material, living body, my transcendence can in turn be transcended by others. Maurice Merleau-Ponty describes the lived body as a third kind "between the pure subject and the object"; the willing and perceiving subject is the body, and this body shows up for others as an object. ${ }^{3}$ As body, I am sensitive to others, undergoing the affective drama of intimacy that includes pleasure, pain, violation, and other responses that arise from contact with others.

Ambiguity describes how the body is minded and the mind is embodied, calling into question the dualism between the two. And yet, the distinction between subject and object persists in experience, where subjectivity and objecthood — and agency and passivity — are lived as being in tension. This indicates how, though mind-body dualism is untenable as a metaphysical claim, the subject/object distinction remains as what Nancy Bauer calls a "phenomenological dilemma," which is lived out in the perspectival character of embodied, subjective experience. ${ }^{4}$ An individual is bound to a first-person perspective, unable cognitively to grasp themselves as both subject and object. And yet we feel that we are both subject and object. Ambiguity appears to us in experience as this felt duality, though we lack a corresponding cognitive grasp of it (because we cannot grasp ourselves as objects, as will be detailed later in this section). 
Attention to ambiguity also reveals the intertwining of passivity and activity in everyday experience. As ambiguous, the person is not sometimes active and other times passive. Rather, as Merleau-Ponty puts it, "we are entirely active and entirely passive." 5 Touching and being touched, for instance, involve a simultaneous sense of being felt from within and being accessible from without. ${ }^{6}$ The touched body is also a touching body: the activity of touching is situated in the passivity of being touched. Activity is indeed a taking-up of my situation, and hence only transcends the situation by virtue of being rooted in it. Put differently, the body's vulnerable openness to others is intertwined with its agency. For the lived body, passivity and activity are not opposed; moreover, objecthood is not merely a passive state to be contrasted with the willful activity of subjectivity.

The intertwining of passivity and activity in embodied consciousness is not felicitously rendered in English, a language with a strong distinction between the passive and active voice. French phenomenologists frequently render it with the reflexive verb se faire. Se faire can be translated into English alternatively as 'to make oneself' or as 'to be made,' but French captures both senses at once, better illuminating the ambiguity. Se faire refers to the process of becoming that characterizes consciousness: self-creation happens ongoingly, in an environment with others. Notably for our purposes, this verb is frequently used in phenomenological descriptions of objecthood, as in the phrase se faire objet (to make oneself/to be made object) or, more broadly, se faire être (to make oneself be). This construction suggests that subjects actively take up their constitution as objects even as they do not 'cause' or 'control' their objecthood. ${ }^{7} \mathrm{We}$ simultaneously are vulnerable to others and take up our vulnerability in agential ways.

I first experience my own objecthood through the immediacy of relating to another person: this encounter makes me feel like an object. When looked at by another, for example, I feel known as 
an object by them. Sartre describes how the experience of the look of another is "of the affective order," which is distinct from cognition. ${ }^{8}$ Only the other knows me as an object. ${ }^{9}$ Unable to get around to the 'other side' of my subjectivity due to my limited perspective, I cannot know myself as the object that I am. I will often try to gain knowledge of myself-as-object by objectifying myself: I might look in a mirror and assess how another person would view the attractiveness of my form, or I might touch my skin and wonder how the other would experience it. Yet this project is doomed to failure: seeing or touching myself is phenomenologically different from seeing or touching another person. The best I can do is to feel that I am an object to another without cognitively grasping the character of this objecthood.

In erotic encounters, one may experience oneself as the subject of erotic intimacy-desiring, intending, willing, and experiencing pleasures or pains - and simultaneously as an erotic object that is perceived and acted on by another. Erotic encounters thus disclose ambiguity. Indeed, Beauvoir uses erotic experience as a paradigmatic example: the experience of erotic reciprocity in particular "most poignantly reveals to human beings their ambiguous condition; they experience it as flesh and as spirit, as the other and as subject." ${ }^{10}$ One feels one's objecthood through being the object of the other's desirous activity, and this is intertwined with one's desire for the other.

In mutually erotic encounters, a crucial element of my eroticized self is this feeling of being an object for the other. I feel desired by the other in my body: the other is oriented toward me as attractive. Being taken as an object in this light is not experienced as a simple diminishment of my agency. On the contrary, I fascinate the other inasmuch as I am a desired object-I am the object that orients another's intentions and response. Thus, living one's own erotic objecthood need not be in tension with the experience of being an agent and a consciousness. Indeed, in being an erotic object to another, I can feel myself recognized in the flesh by them. Although, when unwelcome, 
such a feeling of being an object can strip me of my sense of agential efficacy, in other cases it can produce a new or different sense of myself, which might open onto new feelings and enhanced agential possibilities.

Beauvoir describes how the intimacy of positive erotic encounters permits one to feel one's objecthood as compatible with one's subjectivity. ${ }^{11}$ When balanced with the recognition that one's partner acknowledges one's free subjectivity as well, one "recovers her essentialness at the moment she becomes object [se fait objet]."12 Feeling like an erotic object can be liberating, because it offers one an entry point into a crucial side of one's ambiguity that is not otherwise accessible; the presence of another person is needed in order for me to experience myself as an object. Beauvoir's affirmation of erotic objecthood may in part be read as a response to Sartre's more pessimistic account of erotic encounters. Sartre suggests that the feeling of being the object of another's desire is experienced as a threat, to which one responds either by struggling to reassert one's subjectivity or by trying to embrace one's objecthood completely. For Sartre, the latter response is seduction, where I try to fascinate the other with my objecthood. He dismisses such behavior as bad faith, or self-deception, insofar as I pretend to abdicate my freedom of being a subject. Yet, Beauvoir shows us that erotic encounters can provide space for both my subjectivity and my objecthood - and, reciprocally, for both the subjectivity and the objecthood of the desired other.

Talia Mae Bettcher makes a compatible point in her interactional account of "erotic structuralism," which also further clarifies how ambiguity functions to shape the erotic self. Bettcher suggests that accounts of erotic experience tend to overlook the role of the eroticized self by focusing exclusively on attraction to the other. Yet she argues that the content of erotic desire is not reducible to my attraction to an eroticized other (the source of attraction); it additionally 
includes my eroticized sense of self (the locus of attraction), which has an importantly gendered, embodied structure. ${ }^{13}$ Furthermore, the interaction between my eroticized self and my eroticization of another is crucial to the dynamic of sexual encounters. It is not that I am attracted to myself as an object in such encounters, but rather that I experience myself as the locus of my own attraction to the other and as the target of their attraction. I am excited by my exposure to an eroticized other. $^{14}$

While Bettcher does not explicitly thematize the eroticized self as an object, we take her analysis to show how one's sense of erotic selfhood is both agential and receptive: in Beauvoir's terminology, it is ambiguous. While my attraction to another reflects a sense of my own eroticized body-self, that same sense of selfhood is open to the effects of feeling myself eroticized by another. Bettcher suggests that the eroticized self is not attracted to itself but is nonetheless a key element of erotic interest (she terms this the interest/attraction distinction). This distinction illuminates the importance of what we are describing as erotic objecthood, inasmuch as the eroticized self is the embodied target of the other's desire. "Some significant erotic content is not reducible to the 'source of attraction," Bettcher argues, and one's erotic self is part of this content. ${ }^{15}$ Thus, the eroticized self - in part as object of the other-is key to subjectivity in sexual encounters, even as the other is the source of one's attraction.

The ambiguity of being both subject and object is an inherently difficult target for philosophical reflection, and philosophers have tended to overlook or minimize ambiguity's moral significance by thinking about it in terms of familiar distinctions between mind and body or between activity and passivity. In sexual ethics, theorists who set out from a Kantian moral framework tend to locate value in the autonomy of the will, while taking feeling and the senses as secondary, contingent aspects of selfhood. Moral conduct on this view depends on an actor's 
ability to will that their actions respect the autonomous will of another-being an object for another is at most only a problem to be solved, not an integral aspect of the self. Even when a wider range of sexual goods are recognized as warranting respect, as in the work of Martha Nussbaum, those goods are often posited as goods for a person's mind or subjectivity, rather than as part of the integral body-self that is itself the origin of agency. ${ }^{16}$

Theories of "morally transformative" consent depend on a similar simplification: they take certain conditions of the will to change another's obligations, while the phenomenon of being an erotic object drops out of moral consideration entirely. ${ }^{17}$ The risk of such approaches is that erotic embodiment is treated as a good over which each person should have autonomy, rather than the unavoidable setting from which any possible practice of agency or autonomy must emerge. Feminist critical theorists have recently begun addressing the negative political effects of this failure to recognize ambiguity in theorizing consent. For example, overinflating the "moral power" attributed to consenting can obscure the regularity with which women (and others) experience sexual violation within encounters to which they have given consent. ${ }^{18}$ While consent is theorized primarily as a necessary condition of non-harmful sex, it does little to capture the complexities of embodied encounters between persons. Lived erotic encounters sometimes involve ambivalence or partial consent, and they are often shaped by pernicious social structures that, for certain subjects, limit choices and constrain the interpretive resources for understanding what is taking place. ${ }^{19}$ In practice, putting a sharp notion of morally transformative consent at the center of sexual ethics ignores the moral significance of ambiguity.

A similar refusal to address ambiguity is also present in many poststructuralist discussions of sexual ethics. Theorists who ground their approach in the theory of Jacques Lacan, in a certain reading of Michel Foucault, or in the thought of Gilles Deleuze sometimes invert the valuation to 
elevate objecthood over subjectivity, but in doing so they retain the two terms' polarity. Some queer theorists in these traditions argue that sexual pleasure has a power to shatter subjectivity in a way that always exceeds the regime of rationality or the morally attuned will. ${ }^{20}$ However, positing the senses as dissolving subjectivity fails to disturb the dualistic view of selfhood; feeling is here still taken to be opposed to rational thought or knowledge. Our analysis above suggests that being an erotic object does disrupt the rationalist's claim that subjectivity and the will are sovereign; in this it resonates with the work of queer feminists like Elizabeth Grosz, Lynne Huffer, and Lauren Berlant. ${ }^{21}$ However, our phenomenologically informed rejection of dualism suggests that the sensing capacities of the body are constitutive of subjectivity, not opposed to it. To elevate the pursuit of pleasures and the materiality of the erotic body as valuable — over and against considerations of agency and subjectivity - is to impose an implicit, libertarian view of relationality and the ethical claims others make on our desires and intentions. Linda Martín Alcoff has diagnosed how libertarian readings of Foucault smuggle in an idealized notion of freedom while producing unacceptable results when used for ethical analysis of sexual violation. ${ }^{22}$

Ambiguity is the condition of possibility both for sexual violation to be experienced as a profound harm and for the joy of "losing oneself" in erotic intimacy. Ann Cahill argues that the responsiveness of the body-self to others is the ground for both the profound injury of rape and the possibility of resilience. She writes, "the intersubjectivity necessitated by a bodily existence includes a vulnerability that rape exploits, but it also includes an openness, an ongoing process of development that limits the power of the rapist." ${ }^{23}$ This is the openness of ambiguity, manifest in the possibility of ongoing narrativizing and meaning-making and in the ability of sexual subjectivity—one's sense of oneself as an agential, sexual being — to adapt and be remade. ${ }^{24}$ Being an object for others is part of this meaning-making process: in shaping narratives, we locate 
ourselves in relation to others, taking up our sense of how those others treat us in dynamic interactions, including (but not limited to) interactions in which I am the object of the other's desire.

\section{Experiencing another as an erotic object}

We have highlighted the significant role played by the feeling of being an erotic object, and how being an object discloses one's embodied sense of ambiguity. It is a common view in sexual ethics, however, that treating another as an object in a sexual encounter is a paradigmatic moral wrong. Feminist theorists have drawn attention to how sexual objectification is a central component of women's subordination to men in many societies, and the project of adequately defining objectification (and distinguishing it from ethically unproblematic eroticism) has become an ongoing philosophical debate spanning several decades. ${ }^{25}$ Objectification is often described as treating a person as a mere object rather than as an autonomous subject or moral person with their own will, interests, and integrity. This seems especially apt for explaining certain sexual harms, particularly those that violate one's agency or freedom. However, our discussion in the previous section suggests that the experience of being an erotic object is far wider and more fundamental to eroticism. Being an erotic object to another makes one vulnerable to agential harms, but it does not of itself entail suffering those harms. There is an important space between the harm of objectification and the perception and treatment of another as an object which should not be overlooked.

Correspondingly, perceiving and treating another as an erotic object should not be conflated with the wrong of objectification. While the harms attributed to objectification can certainly be overlaid on perceiving the other as an object, some nontrivial form of treating others as objects is 
an integral feature of interpersonal perception and relationality. ${ }^{26} \mathrm{I}$ can —indeed, must—perceive others as objects, just as others also perceive me as an object. This should be approached as the starting point for moral reflection rather than as a problem to be remediated or a breakdown in morality that ought to be corrected.

A crucial insight from phenomenology is that other persons are grasped as objects of perception in a way that lays a claim on the perceiver. The body of another is not a mere thing in the world: rather, it is a lived body, and it is present to the perceiver as living. The other person presents themselves as a synthetic totality - a whole that cannot be replicated or understood by considering the particular qualities or parts that hang together in it. ${ }^{27}$ In Sartre's analysis, "the body appears within the limits of the situation as a synthetic totality of life and action." ${ }^{28}$ In this same vein, Merleau-Ponty describes the body of another as exemplifying a cohesion and depth of significance comparable to an artwork rather than a mere physical object. ${ }^{29}$ While mere objects in the world reveal themselves as fungible instruments available for use or enjoyment, other persons show up within perception as integrated, non-fungible wholes. We do not natively experience another person in terms of potential use or enjoyment, but instead as demanding a relational response. The other's body is not merely an object, but rather the bearer of a behavior. ${ }^{30}$ And their behavior solicits us to engage with them, that is, to change our own behaviors and intentions in response.

Whereas an object like a tool or a door handle solicits a response in the sense that it offers affordances for use - available to anyone with hands or other means of grasping — another person solicits in me a response of a different kind. Through their interactive, discursive presence, the solicitation of another is personally addressed to me and invested with ethical significance; in principle, how they perceive me and experience my response to them is an issue for me, even if I 
resolve to treat them with indifference or disdain. ${ }^{31}$ As a living body, the other as an object of my experience implicates me: my perception of the other is dynamically related to them and intertwined with my ethical treatment of them. To say that the other is an object for me is not to say that I perceive them neutrally or 'objectively'; rather, the other is a phenomenal body that is part of my world, which includes me as a body-self as well.

Thus, the other's body is an object for me, but it is an object that materially gestures beyond my access and power over it. The other's perspective is 'over there,' implicated in their embodied behaviors but never accessible to me from within. My response can reach out toward the other's subjectivity but cannot grasp it. The other's body is expressive of agency, but their expressionsspeech, movements, postures, and gestures — do not "consist in giving us the Other's interiority." 32 Instead, the other present to me in their expressive body opens up the field of interaction through discourse, touch, and other forms of relationality. I experience the other's embodied subjectivity in the second person, by virtue of their being an object for me. To perceive someone as an object in this way is to perceive them not as a 'mere' body, but as an affective totality whose movements express agency and intention. Such a body is not a what but a who.

Importantly, the other's body is not a signal that they additionally have a mind or a sign that points to a mental content; rather, the body is enminded in its presence to me as a body. Although I can never grasp the other's subjectivity directly as they experience it, I do receive a direct experience in the second person of their subjectivity in relating to them as a body (object). ${ }^{33} \mathrm{We}$ see here the other side of the "phenomenological dilemma" of subjectivity and objecthood described in the previous section. Just as I can feel that I am an object, but cannot know the object that I am for the other (because I am a subject for myself), so too can I feel the other as a subject, but cannot know the subject that the other is for themselves (because they are an object for me). 
Feeling the other's subjectivity is direct and immediate, and I experience it by being solicited by the other, for whom I am an object. We co-constitute the situation of our encounter as subjects for ourselves and objects for each other. We are synthetic totalities, but we each live out the phenomenological dilemma of ambiguity. Merleau-Ponty writes that our experience of others, for this reason, is "not...ultimately thinkable." ${ }^{34}$ Yet it is directly felt.

Early phenomenologists such as Edith Stein describe this in terms of empathy: one feels the presence of another consciousness when perceiving the other-as-object, even as one cannot put oneself in the perspective of that consciousness. Empathy is a way of describing our feeling of a foreign consciousness as an embodied, synthetic totality. So-called inner experience and gestural expression are continuous; as Merleau-Ponty describes, the grimace on a person's face is a part of the anger that they feel, rather than a sign that points to anger as a content. ${ }^{35}$ As a result, the expressiveness exhibited by another's body as an object of my perception is essentially integrated with their subjectivity. To see another's expression of anger in their face or body language is to sense their anger itself - not as my own anger, but as that of the other. ${ }^{36}$

Moreover, this uniquely relational mode of experiencing the other-as-object is heightened in erotic encounters. As Merleau-Ponty writes, the perception of another as an object is "inhabited by a more secret [perception]: the visible body is underpinned by a strictly individual sexual schema... which is itself integrated into this affective totality. ${ }^{\prime 37}$ The erotic other is not a collection of parts, but an integrated totality to which I find myself attracted in a way that reorganizes my intentions. My desire for the other decenters my perception, drawing me out of myself as if magnetized by the other. Here, the other is an object — the object of my desire — but not as one over which I have a hold. Rather, the other-as-object is the source of my attraction, which in a sense has a hold on me - not because they entice my mind, but because they engage my senses. As noted 
in section one, this attraction toward the other also implicates and facilitates my own subjectivity as a sexual being. Thus, experiencing the other as an erotic object not only involves sensing their subjectivity present through their living body, but it also involves experiencing how my own subjectivity and erotic objecthood depend on them. Erotic encounters are thus co-constituted rather than produced through an intentionality from the side of the desirer alone. How I treat the eroticized other who is the object of my erotic attention cannot be extricated from my own sense of subjectivity and my feeling of being an object to them.

\section{Ethical implications}

In light of the foregoing phenomenological reflections about the role of ambiguity in experience and perception, objectifying treatment— that is, treating another as merely an object or means - indeed constitutes a moral wrong that reflects a disregard for the value-imbued nature of another human being. However, the wrongs of objectification need not arise from the particular failure identified by most theorists - that is, the failure to respect another as autonomous, or as having a will or mind worthy of moral regard. ${ }^{38}$ While agency, the will, and other aspects of another's subjectivity are indeed of vital moral concern, an overinvestment in the ostensibly interior subjectivity as site of moral value leads us to neglect the ethical significance of being an erotic object and treating others as erotic objects-including how the other's bodily presence makes moral claims on me to change my behaviors and intentions.

We propose two insights that can help theories of sexual ethics take seriously the significance of erotic objecthood. First, claims on behalf of the value of sexual autonomy, freedom, or agency should acknowledge that the embodied feeling of being an erotic object plays a constitutive role in those practices. Second, normative claims about ethical treatment in sexual intimacy should 
recognize that valorizing another's subjectivity requires a certain orientation of responsiveness toward another as an erotic object. While the first insight calls for a methodological shift in how theorists approach objectification, the second has substantial ramifications for sexual ethics writ large, especially with respect to the normative significance of consent and other sexual communication.

With the first point, we acknowledge that subjectivity is a crucial aspect of the moral value and appeal of another. Being denied agency in one's sexual encounters is often experienced as a profound violation, and there is a moral obligation to behave toward others in ways that acknowledge the significance of their agency and will. I wrong another personally when I prevent their agency from appropriately influencing our encounter, and the society-wide tendency to subject some people to this treatment-particularly women, BIPOC, sex workers, incarcerated people, and disabled people of all genders - constitutes a widespread injustice. However, the ability to pursue these commitments is limited when theorists focus on agency as solely an aspect of active subjectivity, without recognizing the constitutive role played by passivity and being acted upon by others. Agency is always practiced within a situation of embodied ambiguity beyond one's control, which includes both the condition of being an object to others and the situation of being subjected to features of one's position within a social context.

Conventional discussions of sexual agency, and especially of what is described as sexual autonomy, often focus on the will, rational deliberation, and reasons for action as foundational elements. Our analysis suggests that the felt sense of oneself as an object for others should also be given sustained philosophical treatment. A complex phenomenology of sexual desire and selfrelation can help provide a more nuanced account of agency in sexual intimacy. Further, an appreciation of the significance of being eroticized by another might help shed light on situations 
where agency breaks down, such as where a person is not coerced but is nonetheless unable to assert their boundaries and refuse unwanted touch. The notion of ambiguity provides a phenomenological rather than purely psychological explanation of such situations, which might interact productively with contemporary feminist analyses of power and gender ideology to further enhance their descriptive adequacy. ${ }^{39}$

The ethical significance of treating another as an erotic object is also under-examined in sexual ethics, largely because the notion of objectification associates such treatment with moral harm. In particular, ethicists tend to focus on obligations to another in a sexual encounter in highly intellectual terms. They focus on whether a person's communications can be reasonably interpreted as consenting, whether behaviors or speech acts provide sufficient reasons for another to change their actions, or whether conditions of competence, information, or intentionality have been satisfied in a person's decision to consent to sex. Such a heavy investment in the value of the will as a mental process, taken purely as an "interior" feature of subjectivity, leads to the view that speech is the only reliable medium for making moral claims on one another.

While speech and explicit communication are of undeniable importance for enacting agency, the agency or freedom that endows subjectivity with moral value is also enacted in our bodily comportment. The claim, articulated in section two, that the body-self is a synthetic totality suggests that speech and bodily expressiveness should not be treated as mere indicators or signs to be decoded in order to sniff out the real will or intentions behind another's behaviors. Rather, attending to another's bodily expressiveness in gesture, posture, and movement should be recognized as an ethically significant practice in its own right. Another's bodily presence is a source of meaning- or sense-making, often grasped on the affective level, that can be highly 
significant for the purposes of acting responsibly to them and acknowledging the moral significance of their agency.

This claim makes sense if we reflect on lived experience: people often either pursue or refuse sexual encounters through non-deliberative, habituated modes of expression-postures, gestures, non-verbal utterances, particular tones of voice or cadences of speech-that fall short of the intentional communication that is the focus of most philosophical literature. Similar to more explicit, conventionally recognized expressions of consent or refusal, these oblique modes of sexual communication also solicit changes to another person's actions and intentions.

Perceiving the other-as-object in the way we have described in section two is morally neutral. To grasp another as an object is to receive them as a synthetic totality, and in doing so I cannot help but become oriented toward ethical concerns regarding my treatment of them. The body's movement and expression, including the voice, bring another's agency to bear on me, enabling another to solicit my ethical response. ${ }^{40}$ Because of the kind of object they are, I can in principle feel some aspect of the freedom that is their embodied situation. This is implicit in how I respond to any other person with whom I come into relation in daily life, including how I pick up on a wide range of subtle, contextually dependent meanings and affects that seamlessly shape our relations in everyday communication.

And yet, when grasping another as an erotic object, it is common for these implicit or embodied solicitations to fail to achieve the appropriate response. At least this is the case in the society the authors inhabit, which is shot through with pernicious social norms and gendered expectations around sex. Harms and moral wrongs occur when one refuses to take the other-as-object as a synthetic totality with their own bodily agency. In situations that might be described as objectification, another is treated not just as an object, but as a particular, reductive kind of object: 
as a thing or instrument rather than a living body. We agree with the view that the kind of treatment described as harmful objectification is prima facie morally problematic because it denies the other's freedom or agency. In this sense, our phenomenological account coincides with mainstream feminist views. However, we disagree with the view that the kernel of this wrong is a lack of respect for another as a moral person with the dignity of a rational mind or will. Recognizing another's freedom in sexual intimacy also requires recognizing their erotic objecthood as a living body.

Given the phenomenological claim that we always grasp another as a synthetic whole, the moral failure of treating another as a thing requires explanation. This cannot simply be a question of instrumentalization or treating an ensouled person as merely an object. Rather, the moral failure in question here is that of bracketing the whole of another in favor of pretending that their body is an object in the same manner as non-persons are objects. It is a kind of bad faith, or renunciation of one's capacities, to pretend that the other is merely an object in the instrumental or impersonal sense - that is, a means to my own gratification or a mere aesthetic thing. To take on such a position is not a genuine belief about another or an orientation toward them, but a posture or pretense. When we objectify another person sexually — whether by representing them or treating them a certain way-we do not actually believe they are only a sexual object. Rather, we pretend that they are, and that pretending is propped up by discourses of male sexual entitlement and a libertarian view of one's sexuality and body as property that a person, as proprietor, has a right to dispose of as they see fit. ${ }^{41}$

The increasingly juridical understanding of consent feeds this tendency by encouraging the view that, as long as another person validly consents to a sexual act, their autonomy cannot be harmed by what takes place. The vulnerability and phenomenological significance of the erotic 
body drops out of ethical consideration in such a framing; we are encouraged to think it axiomatic to a person's autonomy that their consent has complete authority over how another treats their body. Most consent-based accounts lack nuanced consideration of the complex processesincluding bodily influences - that shape the will.

Moreover, many moral theorists take culpability and responsibility in sex to hinge on the clarity of another's communications that might come to count as consent or refusal. The bad faith we have described in treating another's body as a thing is reinforced by this limited view of morally salient communication in consent-based sexual ethics, which ignores how another as an erotic object is always grasped as broadly and evidently communicative. If subjectivity is enacted in and through the body, as we claim, then freedom, agency, or the will can be expressed not only through verbal communication but also, importantly, through other cues - nonverbal utterances, bodily gestures, postures, and so forth.

Contemporary social science research has called into question the dominant narrative that sexual violation often results from miscommunication, exposing the role of bad faith in the way men in particular interpret the wider range of women's embodied sexual communications. Researchers have demonstrated that women (and others) often communicate sexual unwillingness, refusal, or ambivalence in subtle and implicit ways that are actually quite similar to the rich communication norms that govern other areas of life. ${ }^{42}$ However, because of ready-made alibis provided by social discourses surrounding sexuality, men often ignore these embodied communications and discursive patterns in sexual encounters. ${ }^{43}$ Here, it seems that a social position of privilege and entitlement enables the bad faith posture of denying one's ability to sense another's agency; the wider meaning of another's bodily expressiveness is ignored, often with grievous effects. 
Most discussions of sexual ethics hesitate to valorize such corporeal expression as ethically decisive - that is, as producing claims on another that generate obligations-largely due to reasonable concerns about ambiguity between sexual desire and the will and the unreliability of interpreting the bodily cues of another. However, attending to bodily expression need not rely on the level of transparency expected of explicit communications of consent: agency is enacted through both bodily and verbal expression, and the two ought not to be considered in isolation. Indeed, ignoring bodily expressiveness encourages the manipulation of another's consent- the kind of maneuvering of another to a "yes" that falls short of coercion but is nonetheless ethically problematic.

When another's bodily and verbal communication are apparently in contradiction, this might indicate that person's genuine ambivalence or the inadequacy of one's own interpretive abilities, and either possibility carries with it an ethical imperative toward hesitation, responsiveness, and ongoing conversation. Thus, this approach does not dismiss the relevance of explicit affirmation and the authority of verbal refusal as components of sexual ethics, but it does suggest that a person ought to have a certain receptiveness or attention to the bodily expression of another, particularly in cases where verbal communication is circumspect. In place of the eroticization of the other's body as passive flesh — which is encouraged by some pervasive, gendered sexual social normsan ethical orientation calls for eroticizing the other's body insofar as it is receptive, as a body that is unified with an agential subjectivity. The receptive flesh actively receives one not as flesh alone but as a living body — that is, it generates possibilities for relationality rather than awaiting like a canvas.

\section{Conclusion}


We have suggested that responses to another's embodied presence and erotic involvement can be morally better or worse, but the moral valence of those responses does not follow only from how they map onto another's authority and dignity as an autonomous subject. Rather, a person's subjectivity in erotic intimacy is intertwined with being an object to another, and the way another appears as a bodily object of perception should be appreciated as morally significant as well. As an aspect of a synthetic totality, the other-as-object embodies the subjective dimensions of their agency, will, and desires. Another grasped as body, gesture, posture, movement, and so forth is contiguous with and inseparable from their subjectivity, and their moral claims solicit the perceiver through that totality. So, moral obligations to another in intimacy spiral out from another's presence, including the expressiveness of their living body, which is more than a bundle of signs that might indicate the content of that person's will or subjectivity. The ethical orientation toward another requires acknowledging this subject-object nature of another person-which they themselves live as ambiguity — and responding to how that sense of another demands changes to one's intentions and behaviors.

The fact that we experience others as objects creates the ineradicable moral risk of harming another through objectification, that is, through denying our own dependence on the other and pretending in bad faith that they are a thing. However, this risk cannot be eradicated through more explicit norms of sexual communication or a more airtight definition of valid consent. People must become more skillful at navigating the ambiguity of intimate encounters, including developing an embodied habituation and attunement to the wider range of expressions of others. While some movement in this direction may be possible through new forms of sex education, a large-scale shift demands feminist transformation of disciplinary institutions, cultural practices, and discursive norms that limit the erotic possibilities of some while investing others with privilege and a sense 
of entitlement. A change to how we theorize sexual ethics can be a part of this shift if sexual ethics can valorize the body's agential expressiveness as a source of responsibility between people while acknowledging the constitutive ambiguity of erotic intimacy.

${ }^{1}$ While feminist analyses do not universally use the template of passivity to describe violation, it is prominent in radical feminist accounts of gender hierarchy, which remain perhaps the dominant lens among theorists examining sexual violence against women.

${ }^{2}$ Beauvoir, The Ethics of Ambiguity, trans. Bernard Frechtman (New York: Citadel Press, 1976 [1947]), 8.

${ }^{3}$ Merleau-Ponty, Phenomenology of Perception, trans. Donald A. Landes (New York: Routledge, 2012 [1945]), 366.

${ }^{4}$ Bauer, "Beauvoir on the Allure of Self-Objectification," in How to Do Things with Pornography (Cambridge, MA: Harvard University Press, 2015), 47.

${ }^{5}$ Phenomenology of Perception, 452.

${ }^{6}$ See Merleau-Ponty, The Visible and the Invisible, trans. Alphonso Lingis (Evanston: Northwestern University Press, 1968 [1964]), 133.

${ }^{7}$ The term 'se faire objet' in Sartre and Beauvoir is often interpreted with a negative valence associated with bad faith and/or situations of oppression (see, for instance, Jennifer McWeeny, "Operative Intentionality," in 50 Concepts for a Critical Phenomenology, ed. Gail Weiss et al. [Evanston: Northwestern University Press, 2020], 256-61). While this is certainly apt in many cases, se faire is also often used as a neutral description of the human condition, especially in its valence of facticity. It is this neutral sense we intend to capture; we discuss the case of bad faith in section three. ${ }^{8}$ Sartre, Being and Nothingness, trans. Hazel E. Barnes (New York: Washington Square Press, 1984 [1943]), 288.

${ }^{9}$ See Being and Nothingness, 350. For a more detailed explanation of the distinction between affect and knowledge in Sartre's account of being-for-others, see Ellie Anderson, "Sartre's Affective Turn: Shame as Recognition in 'The Look,", Philosophy Today (2021).

${ }^{10}$ Beauvoir, The Second Sex, trans. Constance Borde and Sheila Malovany-Chevalier (New York: Doubleday, 2012 [1949]), 416.

11 Ibid.

12 Ibid., 415.

${ }^{13}$ See Bettcher, "When Selves Have Sex: What the Phenomenology of Trans Sexuality Can Teach About Sexual Orientation," Journal of Homosexuality 61, no. 5 (2014): 606.

14 Ibid., 614.

${ }^{15}$ Ibid., 609. A crucial upshot of Bettcher's argument, though outside our purview, is that this erotic self is gendered. Hence, Bettcher argues that gender is inseparable from the erotic structure of sexual encounters.

${ }^{16}$ See Nussbaum, "Objectification," Philosophy \& Public Affairs 24, no. 4 (1995): 249-291. We adopt the term "bodyself” from Ann J. Cahill, Rethinking Rape (Ithaca: Cornell University Press, 2001).

${ }^{17}$ Note that most accounts of morally transformative consent define consent as a performative or communicative act, not merely as a condition of the will. Nonetheless, where consent is understood performatively, the condition of the will is widely agreed to be decisive for the moral validity of consent.

${ }^{18}$ See Nicola Gavey, Just Sex?: The Cultural Scaffolding of Rape (New York: Routledge, 2005); Ann J. Cahill, "Unjust Sex vs. Rape," Hypatia 31, no. 4 (2016): 746-761; and Elise Woodard, "Bad Sex and Consent," in this volume.

${ }^{19}$ See Linda Martín Alcoff, Rape and Resistance (Cambridge: Polity Press, 2018). For a discussion of a variety of limitations of consent discourse, see Ellie Anderson, "Women in Philosophy: The Limits of Consent in Sexual Ethics," Blog of the APA (blog), April 24, 2019, https://blog.apaonline.org/2019/04/24/women-in-philosophy-the-limits-ofconsent-in-sexual-ethics/.

${ }^{20}$ See, for example, Lee Edelman's contribution to Lauren Berlant and Edelman, Sex, or the Unbearable (Durham: Duke University Press, 2013).

${ }^{21}$ See Grosz, Space, Time, and Perversion: Essays on the Politics of Bodies (New York: Routledge, 1995); Huffer, Are the Lips a Grave?: A Queer Feminist on the Ethics of Sex (New York: Columbia University Press, 2013); and Berlant and Edelman, Sex, or the Unbearable.

${ }^{22}$ See Alcoff, Rape and Resistance, 79-95. Alcoff specifically argues against Gayle Rubin, although her argument is equally well-suited as a critique of Janet Halley and others in the contemporary queer theoretical backlash to feminism. 
See also Rosanne Kennedy and Hannah McCann, "Splitting from Halley: Doing Justice to Race, Unwantedness, and Testimony in Campus Sexual Assault," Signs 46, no. 1 (2020): 79-102.

${ }^{23}$ Cahill, Rethinking Rape, 138.

${ }^{24}$ On sexual subjectivity as an agential activity of self-making, see Alcoff, Rape and Resistance, 110-47. On narrative self-making after trauma, see Susan J. Brison, Aftermath: Violence and the Remaking of a Self (Princeton: Princeton University Press, 2002).

${ }^{25}$ See, for example, Nussbaum, "Objectification"; Rae Langton, Sexual Solipsism: Philosophical Essays on Pornography and Objectification (Oxford: Oxford University Press, 2009); and Sally Haslanger, Resisting Reality: Social Construction and Social Critique (New York: Oxford University Press, 2012).

${ }^{26}$ See Ann J. Cahill, Overcoming Objectification (New York: Routledge, 2011).

${ }^{27}$ Sartre, Being and Nothingness, 345-51.

${ }^{28}$ Ibid., 346, emphasis original.

${ }^{29}$ Merleau-Ponty, Phenomenology of Perception, 152.

${ }^{30}$ Ibid., 364.

${ }^{31}$ See Emmanuel Levinas, Totality and Infinity, trans. Alphonso Lingis (Pittsburgh: Duquesne University Press, 1979 [1961]), 187-240.

${ }^{32}$ Ibid., 202, emphasis original.

${ }^{33}$ On how we "co-inhabit others' perspectives" in this way, see Kym Maclaren, "Intimacy as Transgression and the Problem of Freedom," Puncta: Journal of Critical Phenomenology 1, no. 1 (2018): 22.

${ }^{34}$ Merleau-Ponty, Phenomenology of Perception, 382.

${ }^{35}$ Ibid., 190-92.

${ }^{36}$ This suggests a phenomenological solution to the so-called problem of other minds. See Søren Overgaard, "Other People," in The Oxford Handbook of Contemporary Phenomenology, ed. Dan Zahavi (Oxford: Oxford University Press, 2012), 460-79.

${ }^{37}$ Merleau-Ponty, Phenomenology of Perception, 158.

${ }^{38}$ See especially Langton, Sexual Solipsism; and the discussion of sexual objectification in Evaluative Perception, ed. Anna Bergqvist and Robert Cowan (Oxford: Oxford University Press, 2018).

${ }^{39}$ This might support accounts such as those in Gavey, Just Sex?; and Kate Manne, Down Girl: The Logic of Misogyny (New York: Oxford University Press, 2018).

${ }^{40}$ On the embodied basis for the "intervocality" of voice and speech, see Ann J. Cahill and Christine Hamel, Sounding Bodies: Identity, Injustice, and the Voice (London: Bloomsbury, forthcoming).

${ }^{41}$ See Ngaire Naffine, "The Legal Structure of Self-Ownership: Or the Self-Possessed Man and the Woman Possessed," Journal of Law and Society 25, no. 2 (1998): 193-212.

${ }^{42}$ Celia Kitzinger and Hannah Frith, "Just Say No? The Use of Conversation Analysis in Developing a Feminist Perspective on Sexual Refusal," Discourse \& Society 10, no. 3 (1999): 293-316.

${ }^{43}$ See Melanie Beres, "Sexual Miscommunication? Untangling Assumptions about Sexual Communication between Casual Sex Partners," Culture, Health \& Sexuality 12, no. 1 (2010): 1-14; and Rachael O’Byrne, Susan Hansen, and Mark Rapley, “'If a Girl Doesn’t Say “No"...': Young Men, Rape and Claims of 'Insufficient Knowledge,” Journal of Community \& Applied Social Psychology 18, no. 3 (2008): 168-93. 